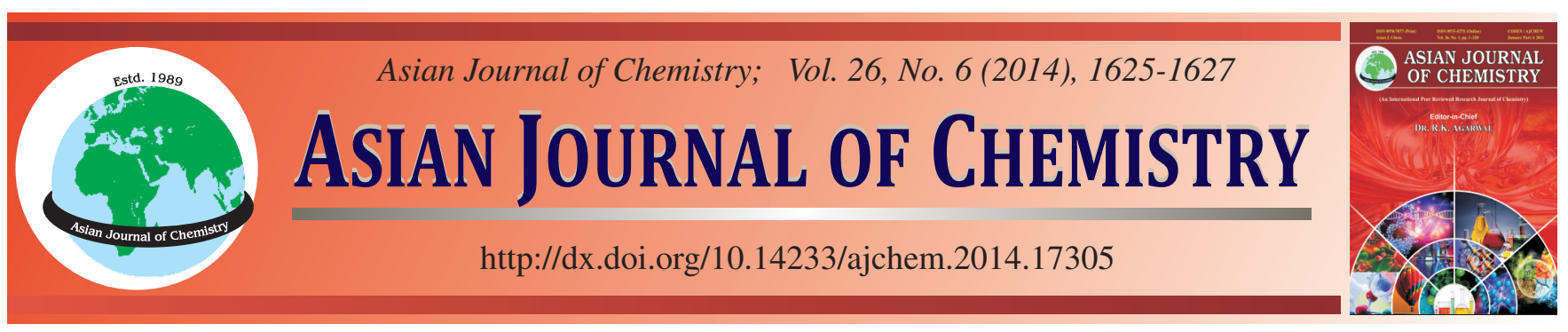

\title{
AZO (ZnO:Al) Transparent Conductive Film Prepared by Plasma Enhanced Chemical Vapour Deposition and its Performances in Comparison with ZnO Film $\dagger$
}

\author{
Zhaoquan Chen ${ }^{1, *}$, Longj Zhu ${ }^{1, *}$, Lingli Hong ${ }^{2}$, ChangGuo XuE ${ }^{2}$, \\ Minghai Liu ${ }^{3}$, Xiaoliang Zheng ${ }^{1}$, Yelin Hu${ }^{1}$, Qiubo Ye ${ }^{1}$ and Xiwei $\mathrm{Hu}^{3}$
}

${ }^{1}$ College of Electrical \& Information Engineering, Anhui University of Science and Technology, Huainan 232001, P.R. China

${ }^{2}$ College of Materials Science \& Engineering, Anhui University of Science and Technology, Huainan 232001, P.R. China

${ }^{3}$ State Key Laboratory of Advanced Electromagnetic Engineering and Technology, Huazhong University of Science and Technology, Wuhan 430074, P.R. China

*Corresponding author: E-mail: zqchen@aust.edu.cn; zhulj@aust.edu.cn

\begin{abstract}
In this paper, $\mathrm{AZO}(\mathrm{ZnO}: \mathrm{Al})$ polycrystalline thin films have been fabricated by PECVD (plasma enhanced chemical vapour deposition) method. Based on PECVD method, the fabrication process of AZO film is shown in detail. Furthermore, the measurements of the film electro-optical properties have been bringing forth, in comparison with $\mathrm{ZnO}$ film. The results suggested that based on PECVD method, AZO films with strong adhesion to the substrate, as low as $89 \Omega / \%$ of square resistance and as high as $85 \%$ of visible light transmittance have been deposited on the glass substrate and the silicon substrate, respectively.
\end{abstract}

Keywords: AZO (ZnO:Al), Plasma enhanced chemical vapour deposition, Transparent conductive film.

\section{INTRODUCTION}

The transparent conductive film is one kind of film materials, which have the advanced performances with electric conduction and optic transmittance in the scope of visible light. $\mathrm{In}_{2} \mathrm{O}_{3}$ film (i.e., ITO) has occupied the leader position in the area of TCO films. Its application scope has involved in the majority of photoelectron component like the flat-panel display, the solar cell, etc. Tin oxide film was used as the TCO film early. But the early $\mathrm{SnO}_{2}$ film has not been doped and then its electrooptical performance is inferior to the doped $\mathrm{SnO}_{2}$ film afterward. Therefore, what obtains the application now is the doped $\mathrm{SnO}_{2}$ thin film and what the doping effect is best are $\mathrm{SnO}_{2}: \mathrm{Sb}$ (i.e., ATO) film and $\mathrm{SnO}_{2}$ : F (i.e., FTO) film. However, this two TCO film have many demerits involving: (1) In and Sn are fewer in nature storage, thus the cost of production will be very high; (2) The chemical properties of In and Sn are lively, the technological conditions will not be easily controlled; (3) The atomic weight of In and Sn are more, the substrate material will be poisoned in the process of the manufacture, especially for the component of the liquid crystal display, the phenomenon of pollution will be very serious. In comparison with those TCO films, the cost of the $\mathrm{ZnO}: \mathrm{Al}$ (i.e., $\mathrm{AZO}$ ) film is low cost, the source of the raw material is richer and nontoxic, its stability is finer than ITO or ATO film, but its electrooptical property can compare with ITO film ${ }^{1}$. Therefore, the research on AZO film has become hotly in TCO domain recently ${ }^{2-5}$

The purpose of this paper is to produce AZO transparent conductive film based on the method of Plasma Enhanced Chemical Vapour Deposition (PECVD). In addition, comparing with the electro-optical property of $\mathrm{ZnO}$ film, the measurements of the film electro-optical properties have been operated.

\section{EXPERIMENTAL}

AZO film fabrication process based on PECVD method: The present work is experiment on PECVD setup as shown in Fig. 1. This experiment adopt the solid state source $\left(\mathrm{CH}_{3} \mathrm{COO}\right)_{2} \cdot \mathrm{Zn} \cdot 2 \mathrm{H}_{2} \mathrm{O}$ and $\mathrm{Al}(\mathrm{OH})\left(\mathrm{CH}_{3} \mathrm{COO}\right)_{2} \cdot 4 \mathrm{H}_{2} \mathrm{O}$ (doping source) as the reaction gaseous matter with carrier gas $\mathrm{N}_{2}$ to the heated substrate. Many active atomic groups have come into being in the vacuum cavity with the plasma produced by the high frequency electric discharges. These groups deposited

†resented at The 7th International Conference on Multi-functional Materials and Applications, held on 22-24 November 2013, Anhui University of Science \& Technology, Huainan, Anhui Province, P.R. China 


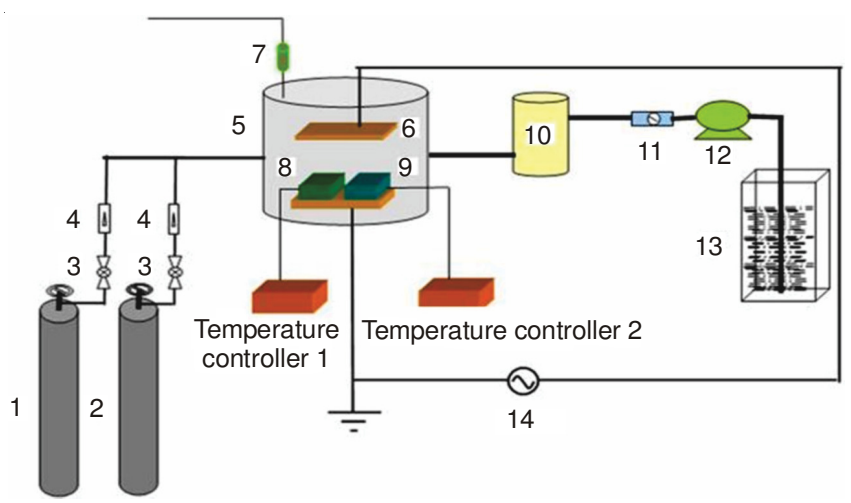

Fig. 1. Diagrammatic drawing of the PECVD system: 1 argon gas; 2 nitrogen gas; 3 relief pressure valve; 4 gas flow meter; 5 reaction cavity; 6 parallel plate electrode; 7 vacuum gauge; 8 platform for heating up the reaction source; 9 platform for heating up the substrate; 10 Filter; 11 Electromagnetic valve; 12 Vacuum pump; 13 waste gas treatment; $14 \mathrm{RF}$ power source

increasingly on the substrate surface produce the $\mathrm{AZO}(\mathrm{ZnO}: \mathrm{Al})$ film as a result of the chemical reaction with active groups on the surface of glass chip. The experimental parameters choose as follows: (1) Carrier gas: argon (Ar) and nitrogen $\left(\mathrm{N}_{2}\right)$; (2) discharging frequency: $40.68 \mathrm{MHz}$; (3) discharging power: $200 \mathrm{~W}$; (4) discharging voltage: $600 \mathrm{~V}$; (5) Gas pressure: 200 Pa; (6) Substrate temperature: $620 \mathrm{~K}$; (7) Solid state source sublimation heating temperature: $570 \mathrm{~K}$; (8) depositing time: $0.5 \mathrm{~h}$.

The film preparation process is operated as follows: (1) Clean and dry the substrate, then lay aside on the substrate platform; meanwhile, install the solid state source in the quartz boat, then put it on the heating up platform; (2) Turns on the total power switch; (3) Opens the vacuum system and turns on the vacuum gauge. Once the reader of the gauge can achieve $10 \mathrm{~Pa}$, the vacuum system work normally; (4) Turns on the valve of the Ar gas and then turns on the power switch to clean the substrate and the entire reaction cavity; (5) Adjusts the supply power and the voltage to produce the stable plasmas; (6) Opens the substrate heating system to achieve the constant substrate temperature; (7) Opens the solid state source sublimation heating system (control the temperature in $570 \mathrm{~K}$ ), turns on the valve of the $\mathrm{N}_{2}$ gas and the film starts to grow; (8) under the scheduled time, shuts down the plasma generator power switch and closes all heating systems; (9) Keep the valve of the $\mathrm{N}_{2}$ gas opening and continually pump the gas (10 min) for eliminating the acidic gas in the cavity; (10) Closes the valve of the $\mathrm{N}_{2}$ gas and then turns off the vacuum system and the total power switch; (11) Waits the sample to the room temperature, then takes out and puts it in a cleanly and aseptic airtight culture dish for result examination.

\section{RESULTS AND DISCUSSION}

Comparison of the film surface appearance: $\mathrm{ZnO}$ film and AZO film have been deposited separately on Si substrate, under the similar experimental condition. From the FSEM (field emission scanning electronic microscope) image (Fig. 2), few Al doping has affected the film superficial appearance greatly. Pure $\mathrm{ZnO}$ film is even with clear crystal boundary and regularly crystal strip, the strip length is $300 \mathrm{~nm}$ and the
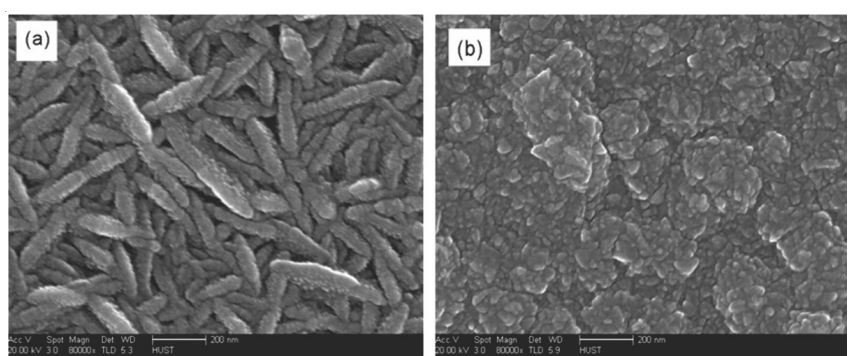

Fig. 2. FSEM image amplified by 80000 times: (a) $\mathrm{ZnO}$ film and (b) AZO film

strip diameter is $40 \mathrm{~nm}$ approximately. But the AZO film presents the reunion phenomenon and becomes the crystal laminated shape.

Comparison of the film crystal structure: As shown in Fig. 3, the X-ray diffraction (XRD) graph: ZnO film is polytropism structure and each diffraction peak position match well with the standard hexagonal system diffraction peak position; after $\mathrm{Al}$ doping, the spiauterite structure of $\mathrm{ZnO}$ film has not changed, the half peak width reduces obviously, the surface diffraction peaks like (100), (002) and (110), all traverse to the high angle compared with pure $\mathrm{ZnO}$ film, besides (101) diffraction peak. That may be deferred that the crystal constant reduces as a result of the $\mathrm{Al}$ introduction and the crystal lattice contract to be distorted, but there have not enough evidence to prove this mechanism at present.
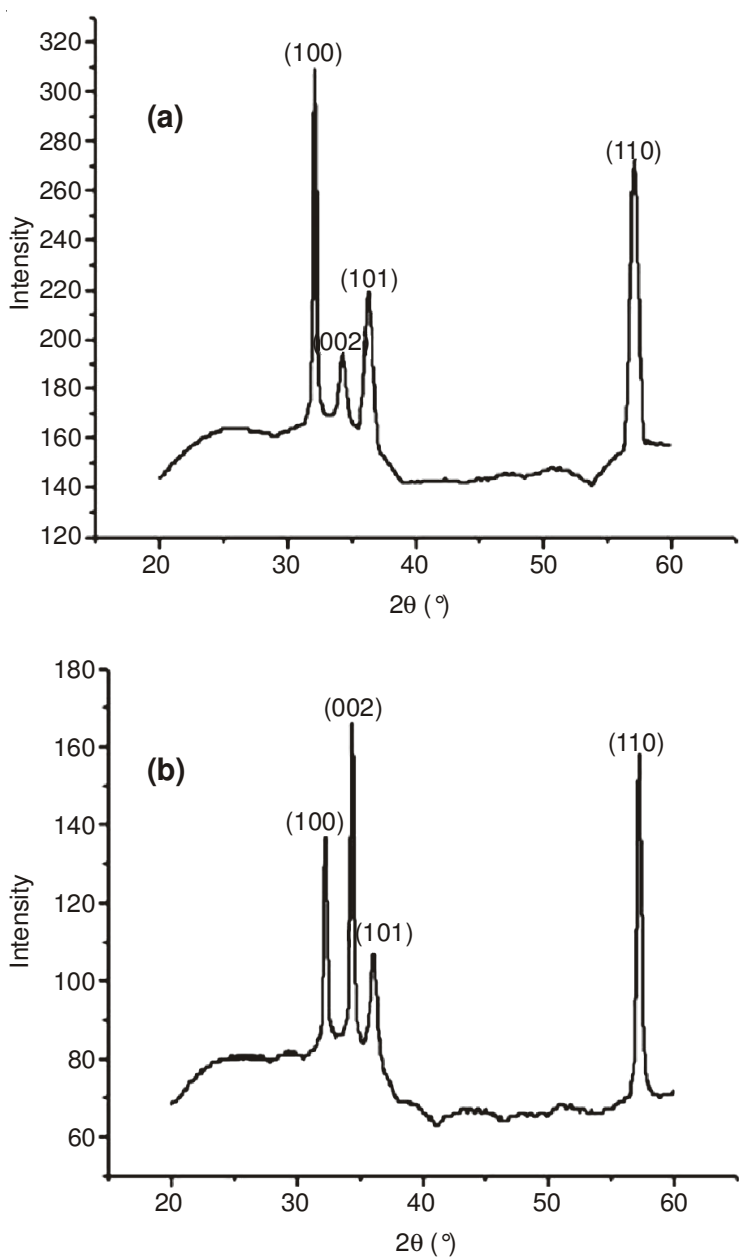

Fig. 3. XRD diagram: (a) $\mathrm{ZnO}$ film and (b) AZO film on the Si substrate 
Comparison of the film optics performance: The intrinsic excitation cannot be occurred and the films are transparent in the visible light scope because that the energy gaps of AZO or $\mathrm{ZnO}$ film is larger than the visible light photon energy (3.1 eV). As shown in Fig. 4(a), it infers that the average transmittance of $\mathrm{AZO}$ film or $\mathrm{ZnO}$ film surpasses $80 \%$ in the wavelength band from 400 to $800 \mathrm{~nm}$; the only difference is the ultraviolet absorption of the AZO film slightly traversing to the short wavelength compared with $\mathrm{ZnO}$ film. This kind of absorption migration may be summed up with BM effect (Burstin-MOSS effect) ${ }^{6}$, namely the density of the current carrier elevates and causes the Fermi energy level carrying to the conduction band.
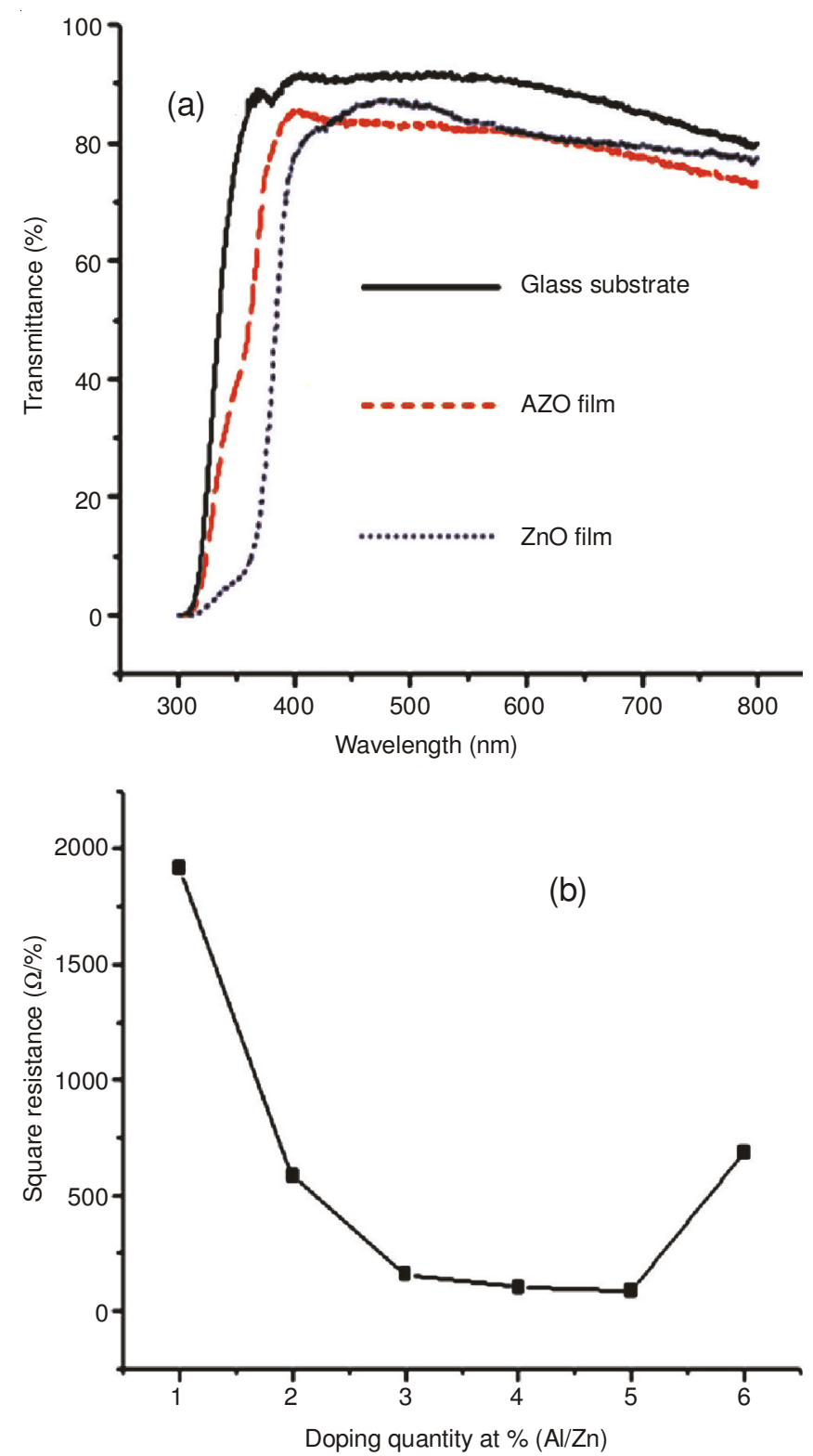

Fig. 4. (a) Optic transmissivity and (b) square resistance
Influence of the doping quantity for the conductivity: The survey discovered that the square resistance of the AZO film is smaller than the $\mathrm{ZnO}$ film without doping as shown in Fig. 4(b). The doping quantity affects obviously the electrical conductivity. When the doping quantity increases from 1 to $3 \%$, the film resistivity reduces largely with lowest square electronic resistivity $89 \Omega / \%$. But the film resistivity cannot reduce infinitely and will increase with higher doping quantity. It is reported in the literature ${ }^{7}$ that the best doping quantity is $4.67 \%$ with the lowest film resistivity. In the AZO crystal film, $\mathrm{Zn}$ ions with positive two chemical valences are displaced by $\mathrm{Al}$ ions with positive three chemical valences. According to the theory of the energy band, the free carrier concentration increase and the resistivity reduce correspondingly due to the electron located at the bottom of the valence band being excited to the conduction band by thermal stimulation ${ }^{8}$. When the doping quantity is excessive, the excessive $\mathrm{Al}$ atoms gather at the crystal boundary, the density of the flaw increase, the ionization scattering strengthens, the Hall transport ratio of the current carrier reduce and finally the film square resistance elevate, as shown in Fig. 4(b).

\section{Conclusion}

This paper presents the AZO film produced by PECVD method. This experiment adopted the solid state source $\left(\mathrm{CH}_{3} \mathrm{COO}\right)_{2} \cdot \mathrm{Zn} \cdot 2 \mathrm{H}_{2} \mathrm{O}$ and $\mathrm{Al}(\mathrm{OH})\left(\mathrm{CH}_{3} \mathrm{COO}\right)_{2} \cdot 4 \mathrm{H}_{2} \mathrm{O}$ (doping source) as the reaction gaseous matter. The $\mathrm{ZnO}$ film with some degree of $\mathrm{Al}$ doping have caused film performance changes in the electricity, optics, structure and surface appearance. These results may be used to explore the optimization design of the solar cell and provide some constructive advice for the next generation of the film photovoltaic products.

\section{ACKNOWLEDGEMENTS}

This work is supported by the Natural Science Foundation of China (Grant No. 11105002), Open-end Fund of State Key Laboratory of Structural Analysis for Industrial Equipment (Grant No. GZ1215), Natural Science Foundation for University in Anhui Province of China (Grant No. KJ2013A106) and Doctoral Scientific Research Funds of AUST.

\section{REFERENCES}

1. R. Groenen, J. Löffler, P.M. Sommeling, J.L. Linden, E.A.G. Hamers, R.E.I. Schropp and M.C.M. van de Sanden, Thin Solid Films, 392, 226 (2001).

2. A. Stadler, Materials, 5, 661 (2012).

3. A.N. Banerjee and K.K. Chattopadhyay, Central Eur. J. Phys., 6, 57 (2008).

4. H.J. Jin, M.J. Song and C.B. Park, Physica B, 404, 1097 (2009).

5. Z.H. Qiao, C. Agashe and D. Mergel, Thin Solid Films, 496, 520 (2006).

6. J.F. Chang and M.H. Hon, Thin Solid Films, 386, 79 (2001).

7. S.Y. Kuo, W.C. Chen, F.I. Lai, C.P. Cheng, H.C. Kuo, S.C. Wang and W.H. Hsieh, J. Cryst. Growth, 287, 78 (2006).

8. O. Kluth, B. Rech, L. Houben, S. Wieder, G. Schöpe, C. Beneking, H. Wagner, A. Löffl and H.W. Schock, Thin Solid Films, 351, 247 (1999). 